\title{
Macrophages in proliferative vitreoretinopathy and proliferative diabetic retinopathy: differentiation of subpopulations
}

\author{
Peter Esser, Klaus Heimann, Peter Wiedemann
}

\begin{abstract}
Macrophages have long been known to play a major role in the pathogenesis of proliferative vitreoretinal disorders. Using the monoclonal antibodies EBM11 (pan macrophage), 27E10 (early inflammatory stage marker), and RM3/1 (healing phase marker), different subpopulations of macrophages were differentiated in surgically removed membranes from patients with macular pucker $(n=6)$, proliferative vitreoretinopathy (PVR) following rhegmatogenous retinal detachment $(n=11)$, traumatic

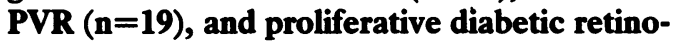
pathy (PDR) $(n=11)$. Macrophages were predominantly found in traumatic PVR and PDR. Some healing phase (RM3/1) macrophages were detected in all disease entities. Inflammatory stage macrophages (positive staining for 27E10) could not be detected in PVR following rhegmatogenous retinal detachment and idiopathic macular pucker. In traumatic PVR inflammatory stage macrophages were associated with a short history of disease whereas in PDR all types of macrophages could be detected regardless of clinical history and duration of the disease.

(Br F Ophthalmol 1993; 77: 731-733)
\end{abstract}

Occurrence of macrophages in epiretinal membranes from patients with proliferative vitreoretinopathy is a long known fact that has been documented by morphological studies ${ }^{1}$ and immunostaining. ${ }^{2}$ Experimental data indicate
Accepted for publication

13 July 1993

Department of
Vitreoretinal Surgery,
University Eye Clinic
Cologne, Cologne,
Germany
P Esser
K Heimann
P Wiedemann
Correspondence to:
P Wiedemann, MD,
Abteilung für Netzhaut- und
Glaskörperchirurgie der
Universitätsaugenklinik,
Joseph-Stelzmann Strasse 9,
D-5000 Köln 41, Germany.
Accepted for publication
13 July 1993

Table 1 Proliferative diabetic retinopathy

\begin{tabular}{|c|c|c|c|c|c|c|c|}
\hline No & $\begin{array}{l}\text { EMB11 } \\
\text { (pan macrophage) }\end{array}$ & $\begin{array}{l}27 E 10 \\
\text { (inflammatory } \\
\text { phase } \\
\text { macrophage) }\end{array}$ & $\begin{array}{l}\text { RM3/1 } \\
\text { (healing } \\
\text { phase } \\
\text { macrophage) }\end{array}$ & $\begin{array}{l}\text { Type of } \\
\text { diabetes }\end{array}$ & $\begin{array}{l}\text { Duration } \\
\text { LC of } \\
\text { diabetes } \\
\text { (years) }\end{array}$ & $L C$ & $P P V$ \\
\hline 1 & ++ & + & + & II & 3 & $\mathrm{y}$ & $\mathbf{n}$ \\
\hline 2 & + & $(+)$ & + & I & 4 & $\mathrm{y}$ & $\mathrm{y}$ \\
\hline 3 & ++ & ++ & - & II & 4 & $\mathbf{y}$ & n \\
\hline 4 & + & - & + & II & 10 & $\mathrm{n}$ & $\overline{\mathbf{n}}$ \\
\hline 5 & ++ & + & $(+)$ & II & 15 & $\mathrm{y}$ & $\mathbf{y}$ \\
\hline 6 & - & - & - & I & 15 & y & $\mathrm{n}$ \\
\hline 7 & + & + & + & II & 17 & $\mathrm{y}$ & $\mathbf{y}$ \\
\hline 8 & ++ & + & + & I & 18 & y & $\mathrm{n}$ \\
\hline 9 & + & - & + & II & 20 & $\mathrm{n}$ & $\mathbf{n}$ \\
\hline 10 & ++ & + & $(+)$ & II & 21 & $\mathrm{y}$ & y \\
\hline 11 & + & - & - & I & 30 & $\mathrm{y}$ & $\mathrm{n}$ \\
\hline
\end{tabular}

Staining intensity: $++=$ Large number of macrophages detected throughout the membrane. $+=\mathrm{Few}$ macrophages scattered over the membrane or cluster of macrophages. $(+)=$ Single macrophage. $-=$ No staining detected.

Duration $=$ duration of diabetes before operation in years. Type=diabetes type I, diabetes type II. $\mathbf{L C}=$ previous laser coagulation $(\mathrm{y}=\mathrm{yes}, \mathrm{n}=\mathrm{no}) . \mathrm{PPV}=$ previous surgical intervention $(\mathrm{y}=\mathrm{yes}, \mathrm{n}=\mathrm{no})$. the involvement of macrophages in the pathogenesis of proliferative vitreoretinopathy (PVR) ${ }^{34}$ However, macrophages have yet to be identified immunohistochemically in tissue derived from patients with proliferative diabetic retinopathy (PDR) and macular pucker.

Since PVR is a multistage disease process with a great variety in the time course of progression to traction retinal detachment, the search for specific markers of disease severity and inflammatory stages seems to be vital for a better understanding of PVR. In the following study we report the different prevalence of two macrophage markers, 27E10 (an early inflammatory stage marker) and RM3/1 (a healing phase marker), in different proliferative vitreoretinal disease entities and correlate our findings with clinical history and duration of the disease process.

\section{Material and methods}

Epiretinal membranes were obtained from patients undergoing vitrectomy for a variety of vitreoretinal disorders. The membranes were immediately frozen at $-70^{\circ} \mathrm{C}$ and cut on a cryostat with subsequent acetone fixation for 10 minutes.

The general immunostaining procedures were performed as described previously. ${ }^{5}$ Antibodies were diluted in phosphate buffered saline containing $0.5 \%$ bovine serum albumin. The following mouse derived antibodies and dilutions were used:

Anti RM3/1 (healing phase macrophage), Biomedicals AG 1:20 Anti 27E10 (inflammatory phase macrophage), Biomedicals AG 1:20 Anti EBM11 (pan-macrophage), Dakopatts

The primary antibodies were labelled with a biotin-streptavidin system.

Antimouse-biotin(Dakopatts)
Streptavidin-alkaline phosphatase (Dakopatts)

Alkaline phosphatase was visualised using the fast red stain. Counterstaining was performed with haematoxylin and eosin. Negative controls were performed by exchanging the primary antibody with mouse IgG.

Results

In most of the diabetic membranes (10/11) macrophages could be detected by the pan macrophage antibody EBM11 regardless of duration or 
type of diabetes. In many cases (5/11) macrophages could be detected in large numbers scattered throughout the membranes. Inflammatory stage macrophages (7/11) and healing phase macrophages $(8 / 11)$ were identified in several membranes. However, no correlation between type of diabetes or medical history and the appearance of a certain subtype of macrophage could be detected (Table 1 ).

In PVR following rhegmatogenous retinal detachment with scleral buckling procedures and in idiopathic macular pucker, no inflamma-

Table 2 Proliferative vitreoretinopathy following rhegmatogenous retinal detachment

\begin{tabular}{cllll}
\hline & \multicolumn{5}{c}{$\begin{array}{l}27 E 10 \\
\text { (inflammatory }\end{array}$} & $\begin{array}{l}\text { RM3/1 } \\
\text { (healing phase }\end{array}$ \\
No & $\begin{array}{l}\text { EMB11 } \\
\text { (pan macrophage) }\end{array}$ & $\begin{array}{l}\text { Duration } \\
\text { macrophage) }\end{array}$ & $\begin{array}{l}\text { macrophage) } \\
\text { (months) }\end{array}$ \\
\hline 1 & $(+)$ & - & $(+)$ & 4 \\
2 & + & - & + & 5 \\
3 & + & - & $(+)$ & 7 \\
4 & - & - & - & 8 \\
5 & - & - & - & 12 \\
6 & + & - & - & 24 \\
7 & - & - & - & 25 \\
8 & - & - & - & 26 \\
9 & $(+)$ & - & - & 26 \\
10 & - & - & - & 30 \\
11 & - & - & - & 98 \\
\hline
\end{tabular}

Staining intensity: $+=$ Few macrophages scattered over the membrane or cluster of macrophages. $(+)=$ Single macrophage. $-=$ No staining detected.

Duration=months elapsed since rhegmatogenous retinal detachment.

Table 3 Idiopathic macular pucker

\begin{tabular}{lllll}
\hline & & $\begin{array}{l}27 E 10 \\
\text { (inflammatory }\end{array}$ & $\begin{array}{l}\text { RM3/1 } \\
\text { (healing phase }\end{array}$ & $\begin{array}{l}\text { Duration } \\
\text { (months) }\end{array}$ \\
No & $\begin{array}{l}\text { EMB11 } \\
\text { (pan macrophage) }\end{array}$ & $\begin{array}{l}\text { macrophage) } \\
\text { macrophage) }\end{array}$ & \\
\hline 1 & - & - & - & 8 \\
2 & $(+)$ & - & $(+)$ & 15 \\
3 & - & - & - & 16 \\
4 & - & - & - & 20 \\
5 & - & - & - & 21 \\
6 & - & - & - & 28 \\
\hline
\end{tabular}

Staining intensity: $+=$ Few macrophages scattered over the membrane or cluster of macrophages. $(+)=$ Single macrophage. membrane or cluster of $m$.
$-=$ No staining detected.

Duration $=$ months elapsed since first diagnosis.

Table 4 Traumatic proliferative vitreoretinopathy

\begin{tabular}{|c|c|c|c|c|c|}
\hline No & $\begin{array}{l}\text { EMBIII } \\
\text { (pan macrophage) }\end{array}$ & $\begin{array}{l}27 \text { E10 } \\
\text { (inflammatory } \\
\text { phase } \\
\text { macrophage) }\end{array}$ & $\begin{array}{l}R M 3 / 1 \\
\text { (healing phase } \\
\text { macrophage) }\end{array}$ & Medical history & $\begin{array}{l}\text { Duration } \\
\text { (months) }\end{array}$ \\
\hline 1 & ++ & + & - & iofb, ppv, lc & 4 \\
\hline 2 & $(+)$ & - & - & iofb, ppv, sili & 4 \\
\hline 3 & + & + & $(+)$ & iofb, ppv, lc & 4 \\
\hline 4 & ++ & ++ & - & lc, cryo & 4 \\
\hline 5 & + & + & - & ppv, sili & 4 \\
\hline 6 & - & - & - & iofb, ppv, sili & 5 \\
\hline 7 & ++ & + & + & iofb, ppv, sili, cryo & 5 \\
\hline 8 & - & - & - & cryo,lc & 5 \\
\hline 9 & + & + & + & iofb, ppv, sili, lc & 6 \\
\hline 10 & ++ & ++ & + & ppv, cryo & 6 \\
\hline 11 & ++ & ++ & + & iofb, ppv, sili, lc & 8 \\
\hline 12 & + & $(+)$ & $(+)$ & ppv, cryo, sili, lc & 9 \\
\hline 13 & - & - & - & ppv, sili & 12 \\
\hline 14 & - & - & - & ppv, sili, lc & 12 \\
\hline 15 & - & - & - & iofb, gas & 14 \\
\hline 16 & + & - & $(+)$ & iofb, ppv, sili & 24 \\
\hline 17 & - & - & - & ppv, sili, lc & 29 \\
\hline 18 & - & - & - & iofb, ppv & 72 \\
\hline 19 & $(+)$ & - & - & iofb, cryo, ppv & 72 \\
\hline
\end{tabular}

Staining intensity: $++=$ Large number of macrophages detected throughout the membrane. $+=$ Few macrophages scattered over the membrane or cluster of macrophages. $(+)=$ Single macrophage. $-=$ No staining detected.

Duration = months elapsed since trauma or last surgical intervention

Medical history: iof $=$ intraocular foreign body; $c r y o=$ cryocoagulation; $l c=$ laser coagulation; $\mathrm{ppv}=$ pars plana vitrectomy; gas = fluid gas exchange; sili=silicone oil tory stage macrophages (27E10) could be detected. Only in three cases of PVR after rhegmatogenous retinal detachment with the shortest history of progression from scleral buckling procedures to epiretinal proliferation and in one case of idiopathic macular pucker was positive labelling of macrophages with RM3/1 observed (Tables 2 and 3).

In traumatic PVR most of the membranes (12/ 19) reacted positively with the pan macrophage antibody EMB11. Interestingly, most of the patients with positive labelling of EMB11 (pan macrophage) and 27/E10 (inflammatory macrophage) had a medical history of less than 9 months between traumatic event or surgical intervention and traction retinal detachment caused by PVR. Only seven cases demonstrated positive labelling for the healing phase macrophage (RM3/1). In these patients, retinal surgery had been performed between 4 and 24 months after the initial traumatic event. In six membranes of traumatic origin, healing phase and inflammatory phase macrophages could be localised in parallel sections. We could not detect any connection between the type of previous surgery and the occurrence of a certain subtype of macrophages (Table 4).

\section{Discussion}

Multiple studies ${ }^{1-9}$ have suggested a major role of macrophages as the primary driving force in the pathogenesis of PVR. Macrophages are not only able to stimulate chemotaxis and induce fibroplasia through secretion of fibronectin and leucotrienes, but they also influence cellular proliferation through the synthesis of platelet derived growth factor (PDGF), fibroblast growth factor (FGF), interleukin 1 (IL-1) and transforming growth factor beta (TGF- $\beta$ ). ${ }^{1011}$ However, the mononuclear phagocyte system comprises a wide variety of different cells. Even culture procedures may exert influence on the functional state of macrophages. ${ }^{12}$ Therefore the use of monoclonal antibodies on cryostat sections as performed in our series of experiments may provide knowledge of the actual functional state of macrophages at the time of surgical intervention.

In all membranes, where macrophages were detected, a positive labelling with the EBM11 antibody was observed. This is not surprising, since EMB11 has been shown to be broadly reactive with most cells of the mononuclear phagocyte system. ${ }^{13}$ However, several membranes with positive labelling of EMB11 did not show. reactivity with either $27 \mathrm{E} 10$ or $\mathrm{RM} 3 / 1$. Although the function of RM3/1 positive macrophages has yet to be determined, the tissue distribution of these macrophages in an experimental model of gingivitis was associated with the healing phase of tissue following inflammation and the down regulatory phase of immune response. ${ }^{14}$ On the contrary large numbers of 27E10 positive macrophages were detected in the acute inflammatory state of the disease. ${ }^{15}{ }^{16}$ Our results confirm previous findings, that macrophage involvement indicated by positive staining of EBM11 is more pronounced in traumatic PVR than in PVR following rhegmatogenous retinal 
detachment. ${ }^{2}$ In traumatic PVR, 27E10 inflammatory macrophages were restricted to the first 9 months after trauma or vitrectomy. This is in accordance with the fact that macrophages have been shown to play the initiating role of the inflammatory process in proliferative vitreoretinal disorders because of their stimulatory secretion products. ${ }^{17}$ In traumatic PVR not only was the number of EBM11 positive macrophages much higher than in PVR following rhegmatogenous retinal detachment and in idiopathic macular pucker, but also the absence of 27E10 positive macrophages indicates a lower degree of inflammatory activity in these disease entities. The colocalisation of $27 \mathrm{E} 10$ and $\mathrm{RM} 3 / 1$ positive macrophages is another clue to the heterogenicity of intravitreal proliferation with inflammatory processes and healing processes taking place at the same time.

The source of macrophages in PVR and PDR, whether blood derived or stemming from resting intraocular cells of the mononuclear phagocyte system like retinal pigment epithelium or microglia, ${ }^{9}$ has yet to be clarified. The positive finding of macrophages in most of the diabetic membranes may be yet another clue to the idea of blood monocytes differentiating into resting macrophages since the disturbance of the bloodocular barrier and intraocular bleeding in diabetic retinopathy allows blood monocytes to enter the vitreous cavity in a great number.

Our finding, that macrophages of the acute inflammatory type (27E10) are more abundant in membranes from patients with a more acute and severe progression of proliferative disease, leads to the conclusion that in the case of new pharmacological concepts steroids may be of crucial importance as an adjunctive treatment to surgical intervention because of their suppression of macrophage synthesis and release of inflammatory cytokines and lysosomal enzymes. ${ }^{18-21}$ In PVR, experimental studies have demonstrated the reduction of traction retinal detachment in eyes following intraocular injection of steroids ${ }^{22}$ or pretreatment with steroids. ${ }^{23}$ In another study, a combination therapy of steroids with the cytotoxic drug daunorubicin significantly lowered the rate of neovascularisation compared with treatment with daunorubicin alone. ${ }^{24}$ Glucocorticoids have also been shown to induce appearance of the RM3/1 subtype in macrophages. ${ }^{25}$ Since this subtype is connected with the healing phase of inflammation and possibly reduced production of prostaglandins in these macrophages, ${ }^{25}$ we agree with other authors ${ }^{26}$ and suggest that an early pharmacological intervention with corticosteroids may be helpful in inhibiting the initial macrophage activation to prevent subsequent cellular migration and proliferation in PVR and PDR.

This study was supported by the Retinovit Foundation and Deutsche Forschungsgemeinschaft (Wi 880/3-2)
1 Kampik A, Kenyon KR, Michels RG, Green WR, de la Cruz ZC. Epiretinal and vitreous membranes. Comparative study of 56 cases. Arch Ophthalmol 1981; 99: 1445-54.

2 Weller M, Heimann K, Wiedemann P. Immunochemical studies of epiretinal membranes using APAAP complexes: evidence of macrophage involvement in traumatic proliferative vitreoretinopathy. Int Ophthalmol 1988; 11: 181-6.

3 Burke JM, Twining SS. Vitreous macrophage elicitation: generation of stimulants for pigment epithelium in vitro. generation of stimulants for pigment epithe
Invest Ophthalmol Vis Sci 1987; 28: 1100-7.

4 Hui YN, Goodnight R, Sorgente N, Ryan SY. Fibrovascular proliferation and retinal detachment after intravitreal injection of activated macrophages in the rabbit eye. $A m \mathcal{F}$ injection of activated macrophages

5 Weller M, Heimann K, Wiedemann P. Demonstration of mononuclear phagocytes in a human epiretinal membrane mononuclear phagocytes in a human epiretinal membrane Graefes Arch Clin Exp Ophthalmol 1988; 226: 252-4.

6 Hiscott PS, Grierson I, McLeod D. Natural history of fibrocellular epiretinal membranes: a quantitative, autoradiographic, and immunohistochemical study. $\mathrm{Br} f$ Ophthalmol 1985; 69: 810-23.

7 Miller B, Miller H, Patterson R, Ryan S. Retinal wound healing. Cellular activity at the vitreoretinal interface. Arch Ophthalmol 1986; 104: 281-5.

8 Pollack A, Korte GE, Heriot WJ, Henkind P. Ultrastructure of Bruch's membrane after krypton laser photocoagulation. II. Repair of Bruch's membrane and the role of macrophages. Arch Ophthalmol 1986; 104: 1377-82.

9 Weller M, Esser P, Heimann K, Wiedemann P. Retinal microglia: a new cell in proliferative vitreoretinopathy? Exp microglia: a new cell in proliff
Eye Res 1991; 53: 275-81.

10 Johnston $R$. Immunology: monocytes and macrophages. N Engl F Med 1988; 318: 747-52.

11 Wiedemann P. Growth factors in retinal disorders, proliferative vitreoretinopathy, proliferative diabetic retinopathy, and retinal degeneration. Surv Ophthalmol 1992; 36: 273-84.

12 Malorny UC, Neumann C, Sorg C. Influence of various detachment procedures on the functional state of cultured murine macrophages. Immunobiology 1981; 159: 327-36.

13 Franklin WA, Mason DY, Pulford K, Falini B, Bliss E, Gatter $\mathrm{KC}$, et al. Immunohistological analysis of human mononuclear phagocytes and dendritic cells by using monoclona antibodies. Lab Invest 1986; 54: 322-35.

14 Zwadlo G, Voegli R, Schulze Osthoff K, Sorg C. A monoclona antibody to a novel differentiation antigen on human macrophages associated with the down-regulatory phase of macrophages associated with the down-regulatory phase of

15 Topoll HH, Zwadlo G, Lange DE, Sorg C. Phenotypic dynamics of macrophage subpopulations during human dynamics of macrophage subpopulations during hum
experimental gingivitis. $\mathcal{F}$ Peridont Res 1989; 24: 106-12.

16 Zwadlo G, Schlegel R, Sorg C. A monoclonal antibody to a subset of human monocytes found only in the periphera blood and inflammatory tissues. I Immunol 1986; 137 $512-8$.

17 Wiedemann P, Weller $M$. The pathophysiology of proliferative vitreoretinopathy. Acta Ophthalmol 1988; 66 (supp 189): 7-15.

18 Leibovich SJ, Ross R. The role of macrophage in wound repair. A study with hydrocortisone and antimacrophage serum. Am f Pathol 1975; 78: 71-100.

19 Werb Z. Biochemical actions of glucocorticoids on macrophages in cultures. Specific inhibition of elastase, collagenase and plasminogen activator secretion and effects on other metabolic functions. $\mathcal{F}$ Exp Med 1987; 147: 1695717 .

20 Lew W, Oppenheim JJ, Matsushima K. Analysis of the suppression of IL-1 $\beta$ and IL-1 alpha production in human peripheral blood mononuclear adherent cells by glucocorticoid hormone. F Immunol 1988; 140: 1895-902.

21 Waage $A$, Baake $O$. Glucocorticoids suppress the production of tumor necrosis factor by lipopolysaccharide-stimulated human monocytes. Immunology 1988; 63: 299-302.

22 Chandler DB, Hida T, Sheta S, Proia AD, Machemer R. Improvement in efficacy of corticosteroid therapy in an animal model of proliferative vitreoretinopathy by pre treatment. Graefes Arch Clin Exp Ophthalmol 1987; 225 : 259-65.

23 Tano Y, Chandler D, Machemer R. Treatment of intraocular proliferation with intravitreal injection of triamcinolone proliferation with intravitreal injection of

24 Chen EP, Steinhorst UH, Samsa GP, Saloupis PT, Hatchell DL. The effect of combined daunorubicin and triamcinolone DL. The effect of combined daunorubicin and triamcinolone acetonide treatment on a refined experimental model of proliferative

25 Zwadlo-Klarwasser G, Bent S, Haubeck HD, Sorg C, Schmutzler $W$. Glucocorticoid-induced appearance of the macrophage subtype RM3/1 in peripheral blood of man. In Arch Allergy Appl Immunol 1990; 91: 175-80.

26 Chandler DB, Rozakis G, de Juan E, Machemer R. The effect of triamcinolone acetonide on a refined experimental mode of proliferative vitreoretinopathy. Am $\mathcal{F}$ Ophthalmol 1985 99: 686-90. 